\title{
TEORIA DEMOCRÁTICA CONTEMPORÂNEA: Modelo Democrático Competitivo e Modelo Democrático Popular
}

\author{
Denisson Silva * \\ Gabriel Setti** \\ Ranulfo Paranhos*** \\ Willber Nascimento****
}

\section{INTRODUÇÃO}

A segunda metade do século XX pode se caracterizar como o momento da ascensão do modelo democrático enquanto forma de governo e tal pressuposto pôde ser corroborado pela queda dos regimes socialistas no final do mesmo século. Nestes termos, o século XX representa a emergência da democracia enquanto a principal forma de governo, com a adesão de praticamente todos os Estados-Nações ocidentais e caracterizado pelo direito dos governados de escolher os governantes. No início do século XXI, cerca de 119 países (correspondendo a 62\% de todos os países do mundo) aderiram a algum modelo democrático (ZAKARIA, 2004).

A partir do final da segunda guerra mundial apresentar-se enquanto um país democrático tornou-se muito comum. Para se ter uma ideia da popularidade, mesmo alguns líderes totalitários se apresentavam como democratas. Duas coisas podem ser

\footnotetext{
* Mestrando em Sociologia - PPGS/UFAL. Graduado em Ciências Sociais - ICS/UFAL. Contato: denissonssilva@hotmail.com

**Professor do Programa de Mestrado em Sociologia da Universidade Federal de Alagoas (PPGS/ICS/UFAL), Doutor em Ciências Sociais. Contato: gabrielsetti@gmail.com ***Professor do Curso de graduação em Ciências Sociais da Universidade Federal de Alagoas (ICS UFAL) e Doutorando em Ciência Política pela Universidade Federal de Pernambuco (DCP - UFPE). Contato: ranulfoparanhos@me.com ****Graduando em Ciências Sociais pela Universidade Federal de Alagoas. Contato: willbernascimento@outlook.com
} 
ditas a esse respeito: (1) a principal característica do século XX foi a emergência da democracia; (2) e não apresentar-se como "democrata" passou a ter uma conotação pejorativa (SEN, 2000). A democracia nunca havia gozado, em nenhum outro período histórico, de tanta aceitação. Mesmo na Grécia clássica havia muita oposição a esse modelo de governo. Nos períodos históricos subsequentes o governo democrático sempre foi visto, no mínimo, com muita desconfiança, senão até mesmo como prejudicial (BOBBIO, 1997). Logo, como entendermos a reviravolta chamada de "a emergência da democracia"?

Este artigo não pretende fazer um levantamento histórico na intenção de explicar o porquê desse posicionamento pró-democracia da maioria dos Estados-Nações no século XX. No entanto, dizemos que a democracia sempre esteve presente nos debates, ora de forma mais intensa, ora mais arrefecida. Em outras palavras, nem sempre a democracia gozou do status de aceitação quanto agora. (SCHUMPETER, 1961; MICHELS, 1968; DAHL, 1989; 1991; 1997; 1998; HUNTINGTON, 1991; HIRST, 1992; BOBBIO, 1997, SEN, 2000; LIJPHART, 2003). Entre os fatores que explicam a aceitação da democracia está (1) o fato do período sangrento que foi a primeira metade do século XX, que gerou um número aproximado de 60 Milhões de pessoas mortas (FERGUSON, 2006) e (2) decadência de regimes totalitários que estiveram presente em todo o século XX. Em resumo, a emergência democrática representou a busca por um modelo que proporcione governos com menor concentração de poder e menos autoritários.

Quais as questões semelhantes e contrárias na literatura acerca da teoria democrática contemporânea? O presente artigo tem como objetivo responder a essa questão através de uma revisão bibliográfica sobre a teoria democrática contemporânea. Por tanto discutimos as principais correntes de pensamento sobre a democracia no pós-guerra.

A partir do que chamamos de "emergência da democracia" tem-se dois polos teóricos: teoria democrática competitiva e teoria democrática popular. $\mathrm{O}$ artigo foi 
dividido de seguinte forma: a seção seguinte faz distinção entre (1) teoria democrática competitiva, com ênfase em Schumpeter (elitismo democrático) e Dahl (pluralismo democrático). A segunda seção trata sobre a teoria democrática popular, cuja obra que receberá maior destaque será "Participação e teoria democrática", de Pateman (participacionista) e "Três modelos normativos da democracia" de Habermas (deliberacionista). A seção do artigo estabelece uma comparação entre os modelos de democracia analisados. A última seção apresenta as considerações finais.

\section{TEORIA DEMOCRÁTICA COMPETITIVA: O MODELO ELITISTA E O MODELO PLURALISTA}

Capitalismo, socialismo e democracia (1961), do autor austríaco Schumpeter, representa o marco do surgimento de uma nova agenda para o debate sobre democracia no pós-guerra. Essa obra significa uma mudança na maneira de pensar a democracia antes e depois da primeira metade do século XX. Tal ruptura deve ser vista como a tentativa de afastamento dos "ideais normativos" de democracia em favor de um debate puramente "empiricista" sobre prática de governo.

Antes da obra de Schumpeter (1961), podemos dizer que já estava se constituindo uma maneira de pensar a democracia enquanto forma técnica. Weber (2004), no início do século XX, atentava para o crescente desenvolvimento da racionalidade nas sociedades modernas, a tendência à tecnicização burocrática de todas as funções do Estado Moderno e para o domínio da estrutura burocrática por parte de funcionários especializados a partir da racionalização burocrática exigida pelas relações sociais no Estado moderno.

Na mesma linha de raciocínio, Schumpeter declara que a democracia deve estar totalmente desvinculada de todo e qualquer caráter normativo, ou seja, deve abandonar o "dever ser" típico da teoria democrática clássica e concentrar a análise sobre "o que é”. O autor não estava preocupado com o valor imputado à democracia pelos teóricos da 
teoria clássica ${ }^{1}$, pelo contrário, sua atenção se voltava para a função do modelo democrático.

Para os teóricos clássicos, a democracia não deve ser vista ou pensada diferentemente de "O governo do povo". Schumpeter é totalmente contrário a essa definição principalmente pelo fato da mesma não condizer com a realidade. Ora, "o povo pode governar"? Mais do que isso, Schumpeter centra suas críticas sobre a defesa dos ideais de bem comum e vontade geral (dos defensores da teoria participativa):

Lembremo-nos de que nossos principais problemas acerca da teoria clássica centravam-se na proposição de que o povo tinha uma opinião definida e racional sobre todas as questões individuais e que ele objetivava essa opinião - numa democracia - escolhendo representantes que zelariam para que essa opinião fosse seguida (SCHUMPETER, 1961: 336).

Além de Schumpeter rejeitar a definição clássica do que seja democracia, ele ainda é contrário aos posicionamentos que atribuem à coletividade o status de racionalidade. Para Schumpeter, "a massa é irracional", os movimentos coletivos são tão racionais quanto uma "manada" e os indivíduos são apáticos em relação à política.

A obra de Schumpeter representa uma ruptura com toda teoria democrática anterior, ou melhor, às de caráter normativo, vinculadas às ideias de valor e de democracia enquanto um fim em si mesmo, defendendo a ideia de que o povo não deve nem pode tomar as decisões políticas como se estivessem na Grécia clássica, mas “decidir" - via eleições - quem vai “decidir” por eles.

Em outras palavras: assumimos a visão de que o papel do povo é produzir um governo, ou melhor, um corpo intermediário que, por sua vez, produzirá um governo ou um executivo nacional (SCHUMPETER, 1961:336).

Percebemos em Schumpeter que é prejudicial à prática democrática a participação popular, justificativa atribuída às experiências de totalitarismo e guerras no

\footnotetext{
${ }^{1}$ Para uma leitura específica dos teóricos da teoria democrática clássica ver Rousseau (1983) e Mill (1981; 1991). Para uma revisão contemporânea da teoria democrática clássica ver Pateman (1992), Sartori (1994) e Dahl (1991; 1998).
} 
decurso do século XX. O papel do indivíduo ou "do povo" resume-se a votar para escolher quem os governará. Schumpeter atribui um grande peso a competição entre elites pelos votos do povo. O fato de as elites apresentarem um número reduzido de indivíduos se comparadas às massas, faz com que elas sejam organizadas e bem mais preparadas a exercerem os cargos políticos, ou seja, a governar (MOSCA, 1954; PARETO, 1954; MICHELS, 1954; PIO \& PORTO, 1997; HOLLANDA, 2011; PERISSINOTO, 2009).

Schumpeter é considerado um elitista por seu modo de observar a relação entre massa $^{2}$ e líderes políticos, que estão vinculados à elite política - que se constituem, nas democracias modernas, como partidos políticos. Nesse sentido, os líderes ou partidos, conseguem se sobrepor às massas por causa de seu tamanho e principalmente por sua capacidade de organização. A massa, por sua vez, é dominada, por sua irracionalidade em assuntos de natureza política.

Desta forma, a função do eleitorado é a de aceitar ou recusar as lideranças políticas. Cabe também acrescentar que essas lideranças (elites), não são absolutas, graças à competição pelos postos de comando mediante o método democrático. Desta maneira, Schumpeter (1961) define o método democrático como "a livre competição entre líderes potenciais pelo voto do eleitorado". Deve-se destacar que essa competição se dá entre políticos profissionais:

Antes de mais nada, segundo a visão que adotamos, democracia não significa e não pode significar que o povo realmente governe, em qualquer sentido mais obvio do termo "povo" e "governo". Democracia significa apenas que o povo tem a capacidade de aceita ou recusar as pessoas designadas para governá-lo (SCHUMPETER, 1984: 355).

\footnotetext{
${ }^{2}$ Segundo Lima (2007), massa traduz a ideia de indivíduos formando um corpo único e homogêneo incapaz de vicular-se ao posicionamento mais reflexivo, ao contrário, estas estão mais diretamente ligadas à ação.
} 
Surge daí uma das principais contribuições teóricas do autor ao debate sobre democracia, não a considerando como um fím em si mesmo, mas um método para alcançar decisões políticas. O método democrático é visto como um acordo institucional para se chegar a decisões políticas onde políticos adquirem o poder de decisão através de uma luta competitiva pelos votos da população.

Ao enxergar a democracia enquanto um arranjo institucional para tomar decisões, atendendo ou não os interesses públicos, Schumpeter representa o marco do procedimentalismo. Nesse contexto, o povo não pode nem deve governar em função da sua incapacidade de organização e do caráter de irracionalidade atribuída às massas. A arena política passa a ser entendida enquanto um mercado econômico cujas elites competem pelo voto dos eleitores e o sufrágio apresenta-se como legitimador do processo democrático.

Downs (1999) reitera que a arena política funciona da mesma maneira que um mercado econômico. Os indivíduos são racionais e se comportam como tal. Partindo deste pressuposto, tanto os políticos quanto os eleitores atuam de maneira a maximizar seus ganhos. Dentro da arena de negociação, os políticos tentam maximizar o apoio à sua agenda política e os eleitores visam maximizar benefícios. A arena política, neste contexto, funciona como um mercado financeiro, onde os partidos políticos e candidatos são produtos e os eleitores são consumidores ${ }^{3}$.

Schumpeter estabelece quatro critérios para o bom funcionamento da democracia. O primeiro se refere à composição da liderança política. Para ele os indivíduos que dirigem a maquina política devem ser dotados de alta qualidade para o exercício de suas funções, além de pertencerem aos estratos sociais que se liguem naturalmente a atividade política. O segundo critério se refere à capacidade dos indivíduos que decidem, isto é, que formam o governo no que diz respeito ao alcance

\footnotetext{
${ }^{3}$ Segundo Downs (1999:50) “os partidos formulam políticas a fim de ganhar eleições, e não ganham eleições a fim de formular políticas”.
} 
das decisões tomadas. $\mathrm{O}$ terceiro critério é uma característica inerente às democracias modernas, isto é, sua necessidade de um corpo técnico-burocrático eficiente e, nas palavras de Schumpeter, "de boa tradição e posição". O quarto critério se refere à necessidade de instituições e do respeito às normas, denominado de "autocontrole democrático" (SCHUMPETER, 1961).

Dahl (1997), ao sistematizar sobre o conceito de democracia, assume, assim como Schumpeter, que a ela é um método político. Construindo sua teoria da Dahl constrói sua teoria da poliarchy - que diverge dos princípios teóricos do elitismo democrático. Segundo o autor, na prática não existem democracias, mas "poliarquias" enquanto modelo teórico aplicável tanto no mundo real (empírico) como elemento prescritivo. Ou seja, quando Dahl se refere a democracia está fazendo referência a termos normativos, e quando se refere à prática do regime democrático, utiliza o conceito de poliarquia.

Assim como Schumpeter, ele percebe a arena política como um cenário de competições constantes pela liderança política. Poliarquia, nesse sentido, pode significar o governo de muitos, que a partir das regras pré-estabelecidas competem pela aprovação do eleitor nos sistemas eleitorais. Por isso as contribuições de Dahl para esse debate só podem ser compreendidas a partir de suas idéias de pluralismo democrático dentro das sociedades. O conceito de poliarquia é formulado em duas dimensões, a prescritiva e a empírica. É nesse sentido que Dahl operacionaliza variáveis para classificar regimes políticos numa escala de duas dimensões. Dessa maneira, sua análise é construída a partir de dois pilares básicos: o da contestação pública e a inclusividade. O conceito de poliarquia é idealizado como mecanismo de avaliação empírica de modelos de governo.

Uma poliarquia é caracterizada como um regime político que possibilita um nível de participação ${ }^{4}$ e de contestação alto. O pluralismo é entendido como a

\footnotetext{
${ }^{41}$ Essa participação do cidadão na vida política no pensamento de Robert Dahl se realizará dentro dos grupos e das associações voluntarias (partidos políticos, ONG's, associação de bairro, etc.), mas não no
} 
possibilidade de diferentes grupos conseguirem poder político. Desta forma, se há competição pelo poder político em diferentes arenas, existe um nível alto de contestação pública, ou seja, oposição. Da mesma maneira - numa poliarquia - também é necessário um alto grau de inclusividade, tanto para os cidadãos que participam de algum grupo, quanto para os que não participam. O principal provedor dessa inclusividade é o sufrágio universal. Uma das principais características de uma poliarquia é a existência de eleições regulares, livres e idôneas. Nisso reside a importância da existência de instituições democráticas que possam assegurar aos governados a possibilidade de não sofrerem excessos (desrespeitos aos direitos) por parte dos governantes (Estado). Em síntese, são os dois eixos básicos, a liberalização e a participação, que possibilitam a democratização dos regimes. E quanto mais altos esses níveis, mais próximo estarão da poliarquia, caracterizada como o máximo de inclusividade com o máximo de contestação ${ }^{5}$.

O conceito de poliarquia pode ser falseável e replicado no que se refere à análise de modelos democráticos. Portanto, dá possibilidade de uma metodologia "mensurar" o grau de democratização dos regimes políticos. Esse procedimento requer as seguintes variáveis: (1) liberdade de formar e de aderir à organizações; (2) liberdade de expressão; (3) direito de voto (sufrágio universal); (4) direito de líderes políticos disputar apoio e votos; (5) fontes alternativas de informação; (6) elegibilidade para cargos políticos; (7) eleições livres e idôneas e (8) instituições políticas democráticas. Todas essas variáveis encontram-se ligadas a três princípios: (1) direito de formular preferências; (2) direito de expressar essas preferências e (3) igualdade no que concerne às suas preferências serem consideradas pelo governo (DAHL, 1997).

Diferente de Schumpeter, Dahl atribui à participação um importante papel na arena da tomada de decisão política. Porém, ambos se aproximam quando analisam que

processo de tomada de decisão direta (casas legislativas, agências de governo, etc.).

5 Nenhuma situação real e histórica alcançou tais níveis. 
tal arena é um espaço de competição pelo poder político. Deve-se salientar que a concepção de Dahl sobre a participação política não repousa sobre a atuação do indivíduo, pelo contrário, a participação na teoria poliárquica está intrinsecamente ligada às associações políticas ${ }^{6}$. Sendo assim, os indivíduos participam através de instituições, nunca fora dela.

Dessa maneira, há um afastamento entre o autor elitista e o teórico pluralista contemporâneo. Schumpeter é pessimista ao avaliar a participação popular nas democracias, enquanto Dahl atribui muita importância à participação. Mas ao mesmo tempo em que se afastam, tornam a aproximar-se no que se refere à competição entre grupos pelo poder político. Ora, se por um lado Schumpeter estava preocupado com o funcionamento da democracia, Dahl preocupa-se principalmente com a democratização da mesma (SARTORI, 1994), onde uma das principais condições para uma poliarquia é a responsividade ${ }^{7}$ por parte dos governos às preferências de seus cidadãos (DAHL, 1997).

\section{TEORIA DEMOCRÁTICA POPULAR: O MODELO PARTICIPACIONISTA E O MODELO DELIBERACIONISTA}

Essa seção apresenta o debate promovido por Pateman (1992) sobre a participação política, bem como, a teoria deliberacionista proposta por Habermas (2001).

Pateman se situa dentro da teoria democrática como representante da corrente participacionista. Em sua obra referenciada a autora trava um debate contra os teóricos da democracia competitiva, principalmente Schumpeter. Uma de suas principais

\footnotetext{
${ }^{6}$ Para uma outra perspectiva sobre a participação e os limites da ação coletiva ver Olson (1965).

${ }^{7}$ Para os interessados no debate ver Manin, Przeworski \& Stokes (1999), Azevedo \& Anastasia (2002) e Miguel (2005).
} 
objeções a esse modelo é a de enxergar a democracia puramente como um método. Outra é a de considerar a teoria participacionista somente como normativa, quando esta teoria se propõe a representar uma atuação efetiva dentro da arena política e da sociedade em geral. Sua preocupação centrava-se na seguinte questão: qual o lugar da "participação" numa teoria de democracia moderna e viável?

Pateman, ao citar Rousseau, apresenta um dos pontos que fundamentam a teoria da democracia participativa. A autora explica que a participação provoca efeitos psicológicos baseados nas interrelações, que por sua vez pode proporcionar melhor funcionamento e qualidade às instituições democráticas:

[...] a participação é bem mais do que um complemento protetor de uma série de arranjos institucionais: ela também provoca um efeito psicológico sobre os que participam, assegurando uma inter-relação continua entre o funcionamento das instituições e as qualidades e atitudes psicológicas dos indivíduos que interagem dentro delas (PATEMAN, 1992:35).

Dessa maneira percebe-se que uma das principais contribuições dessa teoria é sua função social, ou seja, a participação democrática possui um "caráter educativo" e pedagógico, tornando os indivíduos conscientes do seu papel dentro da sociedade, proporcionando interrelação entre indivíduos e instituições que gerariam efeitos psicológicos e influenciarão, de forma positiva, as qualidades tanto das instituições quanto dos próprios indivíduos que participam.

O argumento central é o de que o nível de participação política desenvolvida em âmbito local pode proporcionar um certo nível de educação à sociedade que, por sua vez, influenciará a participação direta na tomada de decisões. Nesse sentido, a autora atribui um elevado grau de importância às relações cotidianas dos indivíduos dentro de seus ambientes de trabalho, como uma das principais esferas de participação. Sendo assim,

Do mesmo modo que a participação na administração do interesse coletivo pela política local educa o indivíduo para a responsabilidade social, também a participação na administração do interesse coletivo na organização industrial favorece e desenvolve as qualidades que o indivíduo necessita para as atividades públicas" (PATEMAN, 1992:50). 
Habermas (2001) dialoga com Pateman, pois ambos estão preocupados com a formação de uma "cultura cívica" dentro da sociedade, que há muito se tem perdido. Tal "cultura cívica" ou "cultura política" 8 refere-se à sua tentativa de resgatar a esfera pública como espaço essencial para os debates entre os indivíduos sobre a política e espaço público para deliberações com a participação dos cidadãos.

Mas como pode ser caracterizada essa esfera pública e qual a sua finalidade? Para Taylor (2000), a esfera pública é um espaço para a discussão de questões importantes que circulam por meios diversos, isto é, neutros, que se situam fora do espectro político. Logo ela prescinde de um espaço físico central para tais debates:

A esfera pública é o lócus de uma discussão que engaja potencialmente todos [...] de modo que a sociedade possa chegar a uma ideia comum acerca de questões importantes [...] A esfera pública é, pois, o lócus em que são elaboradas as concepções racionais que devem guiar o governo. [...] Ela é um espaço de discussão autoconscientemente visto como estando fora do poder (TAYLOR, 2000: 28).

É nesse sentido que Taylor explica a relação entre esfera pública e opinião pública:

A esfera pública gera uma opinião pública que se sustenta surgir da discussão comum, muito embora os participantes nunca se encontrem num dado lugar nem num dado momento. Os intercâmbios dispersos de pequenos grupos, entre os quais circulam materiais impressos, são considerados equivalentes a uma discussão de que surge um senso comum. Uma condição essencial para esse fenômeno da opinião publica dispersa é que os participantes compreendam o que estão fazendo (TAYLOR, 2000:292).

Para Habermas, a ação política deve estar intrinsecamente relacionada à comunicação entre os indivíduos dentro de sua comunidade, atribuindo maior importância ao aspecto comunicacional da esfera política, desta maneira,

Por certo, entre os elementos que formam a política são muito importantes os discursos de auto-entendimento mútuo em que os envolvidos procuram obter clareza quanto à maneira como eles mesmos se entendem enquanto

\footnotetext{
${ }^{8}$ Para interessados em leituras sobre cultura política ou cultura cívica ver: Almond e Verba (1963; 1980), Inglehart (1988), Baquero (2003), Silva \& Setti (2010) e Santos e Rocha (2011).
} 
integrantes de uma determinada nação, membros de certa municipalidade ou Estado, habitantes de uma região etc.(HABERMAS, 2001:276).

O papel da comunicação entre os atores sociais gera a ideia de resgate da esfera pública. Dentro de sua teorização sobre a deliberação pública é impossível dissocia-la a ideia da ação comunicativa, uma vez que é através desse mecanismo que se torna possível o diálogo entre os indivíduos. Mas Habermas deixa claro a dificuldade de se esperar por discursos éticos dentro de sociedades modernas, tendo em vista sua heterogeneidade. Porém, a partir do discurso racional podem-se atingir decisões políticas que não são puramente vinculadas à esfera da ética, cuja ação comunicativa racional é capaz de gerar acordos ou equilíbrios de consenso entre os indivíduos de uma mesma sociedade. Nesse sentido,

O conceito de política deliberativa só ganha referencia empírica quando fazemos jus a diversidade das formas comunicativas na qual se constitui uma vontade comum, não apenas por um auto-entendimento mútuo de caráter ético, mas também pela busca de equilíbrio entre interesses divergentes e do estabelecimento de acordos, da checagem de coerência jurídica, de uma escolha de instrumentos racional e voltada a um fim especifico e por meio, em fim, de uma fundamentação moral (HABERMAS, 2001: 277).

Mesmo Habermas tentando apresentar uma síntese entre o debate liberal versus o debate republicano, pode-se perceber que em seu discurso deliberacionista há, em certa medida, aspectos fundamentais do republicanismo ${ }^{9}$. É importante os aspectos morais da vida política na construção do modelo deliberacionista e na tentativa do resgate da esfera pública. No que se refere ao processo democrático, Habermas, a partir da síntese do modelo liberal e do republicano, expõe o seguinte:

Esse procedimento democrático cria uma coesão interna entre negociações, discursos de auto-entendimento e discursos sobre a justiça, além de fundamentar a suposição de que sob tais condições se almeja resultados ora racionais, ora justos e honestos. Com isso, a razão prática desloca-se dos direitos universais do homem ou da eticidade concreta de uma determinada comunidade e restringe-se a regras discursivas e formas argumentativas que

\footnotetext{
${ }^{9}$ Para uma leitura clássica sobre republicanismo ver Pettit (1999a, 1999b, 2001), Taylor (1979, 2000) e Skinner (1984, 1993, 1999). Para uma leitura contemporânea sobre republicanismo ver Melo (2002), Rawls (1999, 2000, 2001a, 2001b), Elias (2007), Bignotto (2001, 2004) e Nunes e Silame (2007).
} 
extraem seu teor normativo da base validativa da ação que se orienta ao estabelecimento de um acordo mútuo, isto é, da estrutura da comunicação linguística (HABERMAS, 2001:279).

Habermas, assim como Taylor (2000), entende o processo de deliberação vinculado à ideia de esfera pública, que é vista de duas maneiras (AVRITZER, 2000): (1) sentido dialógico e (2) sentido decisionístico ${ }^{10}$.

Em Habermas, existe a preocupação em resgatar os ideais de indivíduos participativos na arena política se posicionando contrario aos ideais liberais no que se refere à relação Estado/sociedade, atribuindo aos indivíduos o papel central nesse processo. Assim como Pateman (1992), Habermas atribui extrema importância à ideia de "cultura participativa" e de "ativismo político", a partir de sua ideia de esfera pública, que poderá proporcionar junto às instituições do Estado espaços de deliberação comum.

Por sua vez, Pateman (1992:54) esclarece que para a democracia participativa " $O$ individuo deve ser capaz de participar em todas as associações que lhe dizem respeito; em outros termos, é necessária uma sociedade participativa”. É nesse sentido uma das maiores contribuições de Pateman em sua revisão de alguns pressupostos da teoria participativa clássica $^{11}$.

Para Pateman, as principais razões em defender uma democracia de modelo participativo são as seguintes: (1) as teorias participativas apresentadas não são puramente normativas, mas planos de ação e prescrições específicas para um governo

\footnotetext{
${ }^{10}$ No modelo decisionista a opinião pública só pode servir para a legitimação dos grupos de líderes. Dentro desse contexto, Habermas percebe que a dominação se legitima, mas nunca se racionalizará como tal.

${ }^{11}$ Apenas se o individuo pudesse se autogovernar no local de trabalho, apenas se a indústria fosse organizada sobre uma base participativa, esse treinamento para a servidão poderia transforma-se em treinamento para a democracia, e o individuo poderia ganhar familiaridade com os procedimentos democráticos e desenvolver as "características democráticas" necessárias para um sistema efetivo de democracia em larga escala (PATEMAN, 1992:56).
} 
realmente democrático; (2) as instituições não podem ser pensadas afastadas dos indivíduos que compõe a sociedade; (3) apenas instituições representativas em âmbitos nacionais, não bastam para a democracia, deve-se existir espaços em organizações locais para a participação efetiva dos indivíduos; (4) a principal função da participação é educativa, tanto nos aspectos psicológicos quanto na aquisição de habilidades para o processo democrático; (5) existência de uma sociedade participativa; e, por fim, (6) a participação (igual) na tomada de decisões. Ou seja, "a justificativa para um sistema democrático em uma teoria da democracia participativa reside primordialmente nos resultados humanos que decorrem do processo participativo”(Pateman, 1992:62).

De forma sumária, por mais que tenhamos enquadrado Pateman e Habermas num mesmo marco teórico, deve-se deixar claro que existem discordâncias da parte do segundo autor em relação ao posicionamento teórico da primeira, principalmente no que diz respeito ao reduzir a participação a um processo meramente pedagógico. Habermas explica que enxergar a participação política somente por seu fator educativo é um posicionamento muito limitado.

\section{DEMOCRACIA COMPETITIVA VERSUS DEMOCRACIA POPULAR: PARTICIPAÇÃO E REPRESENTAÇÃO POLÍTICA, PROCESSO DEMOCRÁTICO E ESTABILIDADE GOVERNAMENTAL}

$\mathrm{O}$ século $\mathrm{XX}$ se tornou o século da emergência da democracia, onde debates sobre o que é e o que deveria ser democracia emergiram em correntes teóricas e críticas acadêmicas. Nestes termos, algumas teorias de democracia se destacaram no cenário contemporâneo: teorias democráticas competitivas (elitistas e pluralistas) e democráticas populares (participacionista e deliberacionista). 
No que se refere à participação e representação ${ }^{13}$ política a teoria democrática participacionista toma como ponto de partida uma dupla patologia das democracias modernas onde a participação ativa dos cidadãos na vida pública surge como a solução. A primeira dessas patologias é a crise da representação política que se refere à sensação dos cidadãos se sentirem cada vez menos representados, o que acaba por gerar a segunda patologia, a da apatia política que se materializa no crescente abstencionismo dos cidadãos na política ${ }^{14}$ (AVRITZER e SANTOS, 2009:3).

Em tese, a participação representa a volta aos "verdadeiros ideais democráticos" atribuindo a esta a essência da democracia. É nesse sentido que tomamos as contribuições da teoria democrática participacionista. Para a resolução das novas tensões sociais existentes nas modernas democracias é importante a abertura de espaços de participação política efetiva. Ou seja, participação efetiva implica dizer que as decisões serão tomadas por aqueles que serão submetidos e elas. Nesse sentido, participação em âmbito nacional não é suficiente, mas também em esfera local a partir de espaços institucionais formais e informais. Para Pateman (1992), a participação política possui um caráter educativo que possibilitará o desenvolvimento das qualidades individuais e até mesmo o próprio desenvolvimento das instituições democráticas ${ }^{15}$.

Se pensarmos sobre a questão da estabilidade no que se refere à participação política, observamos duas avaliações distintas. Do lado democrático competitivo -

${ }^{13}$ Para Anastasia e Nunes (2006:17) "Por representação política se entende o conjunto de relações estabelecidas entre os cidadãos e os governantes eleitos. Os primeiros são, nas democracias, os sujeitos detentores de soberania política e a utilizam para autorizar outros, os governantes, a agirem em seu nome e no nome de seus melhores interesses. Os cidadãos são os mandantes, os governantes são os mandatários, estejam eles no Poder Executivo — presidente, governador, prefeito — ou no Poder Legislativo - senadores, deputados federais, deputados estaduais ou vereadores." Para outras leituras acerca de representação ver Dahl (1991) e Sartori (1994).

${ }^{14}$ Note-se que aqui a apatia política é resultante da baixa representatividade das democracias liberais diferente de Schumpeter que a ver enquanto característica própria da massa.

${ }^{15}$ É justamente isso que se pode ver nas teorias do que se escrevem sobre a democracia participativa: uma serie de prescrições especificas e planos de ação necessários para se atingir a democracia política. E isto se efetua por meio da educação pública, a qual, no entanto, depende da participação em muitas esferas da sociedade na atividade política, entendida num sentido bastante abrangente (PATEMAN, 1992:33). 
retomando Schumpeter - a participação popular é vista como um problema ao funcionamento da democracia, pois os indivíduos são apáticos sobre assuntos políticos e quando atuam em coletividade perdem os sentidos, ou melhor, sua racionalidade. Nesses termos, no pensamento democrático competitivo em sua vertente elitista democrática, a estabilidade do regime se dá a partir de uma confluência de resultados: baixa participação popular (menos chance de totalitarismos) graças à apatia política e irracionalidade das massas; acirrada competição política entre grupos ou partidos, sufrágio universal para que as massas escolham quem governa e centralização decisória dentro das instituições representativas.

Seguindo a linha do elitismo democrático, o pluralismo se diferencia deste no que se refere à participação política. Para Dahl (1998) o fator mais importante para a estabilidade governamental é a competição e a participação política dentro de uma sociedade guiada por instituições democráticas. É justamente a atuação dos indivíduos dentro das associações ou grupos de interesses, dentro de um equilíbrio baseado em regras legais (institucionais e constitucionais), que possibilitará a difusão de poder político na sociedade e a responsividade ${ }^{16}$ dos representantes em relação às preferências ou interesses dos cidadãos. Porém, a participação direta da massa no processo decisório é vista como prejudicial à democracia.

Para os teóricos da teoria democrática popular - o participacionismo e o deliberacionismo - a participação direta é o fator que impede o colapso do sistema. Por um lado, os teóricos participacionistas enfatizam que fatores psicológicos e educativos da participação política são percebidos como limitadores de uma possível instabilidade governamental. Por outro lado, deliberacionistas apontam para a importância do diálogo no que se refere à resolução de conflitos mútuos dentro da arena política.

\footnotetext{
${ }^{16}$ Miguel (2005:28) conceitua responsividade como: "refere-se à sensibilidade dos representantes à vontade dos representados;" ou, dito de outra forma, à disposição dos governos de adotarem as políticas preferidas por seus governados.
} 
No que se refere à participação política, os interesses sociais difusos ${ }^{17}$ e suas relações com a estabilidade, Habermas se aproxima muito da análise feita por Pateman. Para ele a democracia deliberacionista está posta justamente para a resolução de tensões sociais referentes aos interesses de cada grupo. Essas tensões são passíveis de solução quando se busca os acordos mútuos dentro da esfera pública. Mesmo Habermas não sistematizando como se daria tal percurso a partir de moldes empíricos, o elemento "discurso" se apresentará enquanto mediador desse debate.

Do outro lado do espectro teórico, os defensores da teoria democrática competitiva, gozam de certa hegemonia pelo fato de suas teorias basearem-se principalmente na prática democrática real e em sua aplicabilidade. Nesse sentido, Schumpeter e Dahl estão partilhando de um mesmo pensamento: em democracias modernas, de larga escala, é impossível fugir da representação política. Dahl, até mais que Schumpeter, atribui grande valor a atuação dos grupos políticos e associações políticas no que se referem às lutas pelo atendimento de suas preferências.

Schumpeter foi um divisor de águas, estava insatisfeito com a "teoria democrática até aqueles tempos" (SARTORI, 1994) rompendo com a visão normativa desse debate e defendendo a democracia enquanto método político e comparando a arena política a um mercado. É nesse sentido, que para Schumpeter a estabilidade do governo democrático se baseará na disputa eleitoral entre os partidos políticos. Nestes termos, pensar a democracia enquanto um método para alcançar decisões políticas atribuiu funcionalidade tanto ao conceito quanto ao próprio modelo. Ora, se aceitamos que surgem novas demandas sociais a todo instante, pensar a democracia enquanto meio para resolução de dilemas pode ser significativo.

\footnotetext{
${ }^{17}$ Segundo Olson (1965), os interesses de um pequeno grupo de indivíduos possui maiores chances de sucesso/escolha do que os interesses difusos presente na coletividade de indivíduos desorganizados. Do outro lado, Arrow (1951), afirma que a ação coletiva produz necessariamente bens coletivos.
} 
Podemos dizer que Schumpeter não estava pensando no nível de qualidade imputado ao sistema, mas estava apresentando um modelo que se posiciona em favor da estabilidade. Visto seu contexto, sua preocupação era a de não correr o risco de o regime democrático ser tomado por um líder totalitário. E tendo em vista o tamanho das democracias modernas, logo seria inevitável a delegação do poder a representantes eleitos.

Do lado participacionista e deliberacionista a crítica é de que o sistema hegemônico de democracia em seu modelo representativista não é democrático, pois o estado democrático apenas será alcançado quando todas as decisões políticas estiverem nas mãos dos quais serão submetidos a ela. No que se refere à tomada da decisão estar nas mãos do cidadão é praticamente impossível, pois a possibilidade de participação efetiva nos moldes gregos é impraticável em democracias modernas pelo simples fato da quantidade de cidadãos presentes nesses modelos. Nas palavras de Dahl (1998:126), "Indiscutivelmente, em teoria é possível que sistemas políticos muito pequenos obtenham um elevado indice de participação do cidadão a que os sistemas grandes jamais podem corresponder".

Sobre a questão da participação na decisão sobre a coisa pública, Schumpeter acusava os cidadãos de uma apatia política. Posto dessa maneira, podemos perceber que em democracias modernas a melhor alternativa a ser tomada é recorrer ao modelo representativo. Dentro desse debate sobre participação e representação política, Dahl fornece sua maior contribuição. Tomando como pressuposto que os governos devem ser responsivos às preferências de seus cidadãos, a participação se dará em dois momentos: (1) com o sufrágio universal quando o indivíduo escolhe o seu representante e (2) no "antes, durante e depois" das eleições - na medida em que os indivíduos tem o direito de participar de associações buscando seus próprios interesses e/ou de seus grupos.

Dahl esclarece que o bom governo é aquele que consegue implantar em seu regime índices altos de inclusividade e de contestação pública. Em outras palavras, um regime poderá ser considerado uma poliarquia se: (1) são altos os índices de 
participação política e (2) os índices de oposição permitida a tal regime. Desta maneira podemos entender que a teoria democrática competitiva, fornece referencial tanto para a teoria representativa, quanto para a participação política.

Nesse sentido, vale lembrar uma das contribuições centrais da teoria democrática participativa e, diga-se de passagem, um ponto de aproximação entre Pateman e Dahl. Uma das condições para uma sociedade democrática - segundo Pateman - é uma cultura participativa e tal participação não pode nem deve estar atrelada somente no nível nacional, mas em todos os espaços sociais locais. Ou seja, a participação política democrática deve estar presente dentro de todos os grupos e associações.

Quando se fala em processo democrático se fala dos mecanismos de tomada de decisões estabelecidas dentro de uma relação entre meios e fins. No que se refere ao modelo democrático competitivo o processo democrático está intrinsecamente associado às instituições legais do Estado. A tomada de decisões encontra-se nas mãos dos instituídos aos cargos representacionais mediante eleições competitivas, livres e idôneas.

A teoria democrática deliberacionista teoriza o processo democrático em dois momentos e cada um desses momentos possui um sentido (que se refere também ao próprio conceito de deliberação pública em Habermas). O primeiro diz respeito à construção da opinião popular no âmbito da esfera pública. Taylor (1979) reforça essa ideia exemplificando que quando os cidadãos tomam conhecimento dos debates, esse momento é caracterizado pelo sentido dialógico da deliberação, isto é, debate sem tomada de decisão.

O segundo momento acontece dentro de instituições decisórias específicas a cada sociedade mediante o sentido decisionístico da deliberação pública. Nessa concepção, as decisões políticas deverão ser tomadas por aqueles que serão submetidos às mesmas. Logo, mediante o debate discursivo, os cidadãos deverão decidir sobre quais políticas implementar, quando e como implementá-las. A idéia central é que a opinião 
pública, no primeiro momento, em sentido dialógico já estaria dotada de informações sobre os temas a serem deliberados, restando deliberar no sentido decisionístico sobre tais questões. Logo, na teoria democrática deliberacionista o processo democrático é entendido enquanto o meio para as decisões políticas e constituído pelo debate público entre os cidadãos e as instituições do Estado - tanto no sentido dialógico quanto no decisionístico. Para a teoria participacionista o processo democrático também deve se desenvolver a partir da participação direta dos cidadãos nas instâncias decisórias, pois o modelo democrático só pode ser considerado democracia substantiva ${ }^{18}$ quando o povo decide os rumos das políticas que os afetarão.

Deve-se apontar que as teorias do modelo democrático popular, em seu caráter prescritivo, não deixam claras as questões de como seria possível conseguir alcançar os objetivos propostos pela teoria. Para os teóricos democráticos competitivos o processo democrático encontra-se inserido dentro das instituições democráticas estabelecidas. Isto é, se o governo é representativo, a tomada de decisão ocorrerá no âmbito do poder Executivo e do Legislativo. Mas se o modelo for participacionista quais serão as instituições onde o povo decidirá os rumos? Todos os cidadãos poderão decidir? Nesse sentido, a teoria não fornece uma resposta satisfatória.

O quadro abaixo sumariza as principais características do pensamento democrático, dividido nos dois pólos teóricos analisados nesse artigo, no que se refere à participação política, representação política, processo democrático e estabilidade governamental.

Quadro 1 -Síntese das correntes teóricas

\begin{tabular}{|c|c|c|c|c|}
\hline \multirow{2}{*}{$\begin{array}{c}\text { Teoria } \\
\text { democrática }\end{array}$} & \multicolumn{4}{|c|}{ Concepções } \\
\hline & Participação Política & $\begin{array}{c}\text { Representação } \\
\text { política }\end{array}$ & $\begin{array}{c}\text { Processo } \\
\text { democrático }\end{array}$ & $\begin{array}{l}\text { Estabilidade } \\
\text { governamental }\end{array}$ \\
\hline COMPETITIVA & & & & \\
\hline
\end{tabular}

18 Ver: Przeworski (1984) e Hirst (1992). 


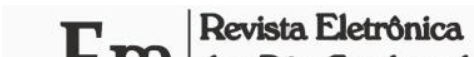 Itmancen Tese $\frac{1}{\text { mine }}$}

\begin{tabular}{|c|c|c|c|c|}
\hline Elitista & $\begin{array}{l}\text { Prejudicial à saúde da } \\
\text { democracia; o povo } \\
\text { deve se limitar a } \\
\text { escolher os } \\
\text { representantes. }\end{array}$ & $\begin{array}{l}\text { Necessária, visto a } \\
\text { irracionalidade da } \\
\text { massa e a grande } \\
\text { quantidade de } \\
\text { cidadãos das } \\
\text { democracias } \\
\text { modernas. }\end{array}$ & $\begin{array}{l}\text { Decisões tomadas } \\
\text { através dos } \\
\text { representantes eleitos, } \\
\text { levando em conta seus } \\
\text { próprios interesses } \\
\text { dentro das instituições } \\
\text { do Estado. }\end{array}$ & $\begin{array}{l}\text { Possível, mediante a } \\
\text { confluência da não- } \\
\text { participação popular, } \\
\text { alcançada pelas } \\
\text { eleições para eleger } \\
\text { representantes, } \\
\text { baseadas na } \\
\text { competição eleitoral } \\
\text { entre os partidos } \\
\text { (elites) e instituições } \\
\text { democráticas. }\end{array}$ \\
\hline Pluralista & $\begin{array}{l}\text { Necessária, visto as } \\
\text { decisões possíveis } \\
\text { tomadas pelos } \\
\text { cidadãos, a partir da } \\
\text { confluência dos seus } \\
\text { interesses através de } \\
\text { associações } \\
\text { constituídas no } \\
\text { processo decisório. }\end{array}$ & $\begin{array}{l}\text { Necessária, visto a } \\
\text { grande quantidade de } \\
\text { cidadãos das } \\
\text { democracias } \\
\text { modernas. }\end{array}$ & $\begin{array}{l}\text { Representantes } \\
\text { eleitos, levando em } \\
\text { consideração as } \\
\text { preferências das } \\
\text { associações de } \\
\text { interesses e dos } \\
\text { cidadãos dentro de } \\
\text { instituições } \\
\text { democráticas. } \\
\end{array}$ & $\begin{array}{l}\text { Estabelecida entre } \\
\text { atuação da sociedade } \\
\text { civil dentro dos grupos } \\
\text { de interesses, } \\
\text { representantes eleitos } \\
\text { mediante competição } \\
\text { eleitoral e instituições } \\
\text { democráticas. }\end{array}$ \\
\hline \multicolumn{5}{|l|}{ POPULAR } \\
\hline Participacionista & $\begin{array}{l}\text { Necessária. Elemento } \\
\text { essencial para as } \\
\text { democracias } \\
\text { modernas. }\end{array}$ & $\begin{array}{l}\text { Prejudicial, visto a não } \\
\text { representação plena } \\
\text { dos interesses } \\
\text { coletivos (crise da } \\
\text { representação). }\end{array}$ & $\begin{array}{l}\text { Decisões tomadas } \\
\text { mediante a } \\
\text { participação direta dos } \\
\text { cidadãos em } \\
\text { instituições } \\
\text { democráticas. }\end{array}$ & $\begin{array}{l}\text { Possível a partir da } \\
\text { cultura política } \\
\text { produzida através da } \\
\text { participação direta na } \\
\text { tomada de decisão. }\end{array}$ \\
\hline Deliberacionista & $\begin{array}{l}\text { Importante quando } \\
\text { mediada pelo diálogo e } \\
\text { debate racionalmente } \\
\text { constituído dentro da } \\
\text { esfera pública. }\end{array}$ & $\begin{array}{l}\text { Assume a importância } \\
\text { exercida pelas } \\
\text { instituições } \\
\text { representativas, bem } \\
\text { como sua maneira de } \\
\text { racionalização. }\end{array}$ & $\begin{array}{l}\text { Decisões tomadas } \\
\text { pelos representantes } \\
\text { nas instancias } \\
\text { decisórias (instituições } \\
\text { representativas do } \\
\text { estado) ou do Estado } \\
\text { mediado a através dos } \\
\text { equilíbrios mútuos } \\
\text { estabelecidos a partir } \\
\text { do diálogo na esfera } \\
\text { pública. }\end{array}$ & $\begin{array}{l}\text { A estabilidade no } \\
\text { modelo deliberativo } \\
\text { se relaciona a } \\
\text { estabilidade das } \\
\text { decisões devido aos } \\
\text { múltiplos consensos } \\
\text { na esfera pública } \\
\text { que, de alguma } \\
\text { maneira, pode ser } \\
\text { refletido no } \\
\text { parlamento. }\end{array}$ \\
\hline
\end{tabular}

Fonte: elaboração dos autores.

\section{CONSIDERAÇÕES FINAIS}

Este artigo apresentou uma reflexão sobre dois pólos teóricos de democracia contemporânea: teoria democrática competitiva (elitista e pluralista) e teoria democrática popular (participacionista e deliberacionista), respondendo a questão sobre semelhanças e diferenças na literatura da teoria democrática contemporânea. Apresentamos, ainda, a necessidade e a importância do debate acerca da teoria democrática no que se refere à emergência da democracia (modelos democráticos) 
como o sistema político emergente da segunda metade do século XX, sobretudo nos países ocidentais.

Sumariamente, dentro de ambas correntes teóricas é possível notar a presença dos autores Schumpeter e Dahl - do lado democrático competitivo (o primeiro enquanto elitista e o segundo enquanto pluralista) - e Pateman e Habermas - do lado democrático popular (a primeira referenciada como participacionista e o segundo enquanto deliberacionista). No sentido didático, nos esforçamos para sistematizar as informações referente às correntes da teoria democrática estabelecendo comparações entre marcos teóricos e, mais especificamente, comparações dentro da própria corrente de pensamento.

Por fim, apresentamos as limitações desse artigo quando afirmamos que não tentamos esgotar aqui as possibilidades de análises referentes a essas teorias. Pelo contrário, apresentamos uma revisão com foco na comparação, afim de assegurar maior esclarecimento aos pesquisadores interessados em fazer desenhos de pesquisa a partir desse debate.

\section{REFERENCIAS}

ALMOND, G. \& VERBA, S.. The Civic Culture: Political Attitudes and Democracy in Five Nations. Thousand Oaks, Sage Publications, 1963.

ALMOND, G. . The Intellectual History of the Civic Culture Concept. In: ALMOND, G. e VERBA, S. The Civic Culture Revisited. Thousand Oaks, Sage Publications, 1980.

ANASTASIA, F. e NUNES, F. "A representação da reforma.” In: Avritzer, L.; e Anastasia, F. (Orgs.). Reforma política no Brasil. Belo Horizonte: Editora UFMG, 2006 págs. 17-33.

ARROW, K. Social choice and individual values. New Haven: Yale University Press, 1951 
AVRITZER, L.. Teoria Democrática e Deliberação Pública. Lua Nova - Revista de Cultura e Política n $^{\circ}$ 50, São Paulo: CEDEC, 2000 p. 25-46.

AVRITZER, L. e SANTOS, B de S.. Introdução: para ampliar o cânone democrático. Curso de Formação de Conselheiros Nacionais. SGPR/UFMG., 2009 Disponível em: www.eurozine.com. Acesso em: jun 2013

AZEVEDO, S. D., \& ANASTASIA, F. “Governança, accountability e responsividade: reflexões sobre a institucionalização da participação popular em experiências desenvolvidas em Minas Gerais". Revista de Economia Política, 2002 79-97.

BIGNOTTO, N.. Origens do Republicanismo Moderno. Belo Horizonte: Ed. da UFMG, 2001

BIGNOTTO, N. Problemas atuais da teoria republicana. In CARDOSO, S. (Org). Retorno ao republicanismo. Belo Horizonte: Ed. da UFMG, 2004 pp 17-43.

BIGNOTTO, N. "Construindo outra sociedade: o capital social na estruturação deuma cultura política participativa no Brasil”. Rev. Sociol. Polit. N.21, 2003 pp. 83-108.

BOBBIO, N. A teoria das formas de governo. $9^{\mathrm{a}}$ ed. - Brasília:Editora da UnB, 1997

DAHL, R. Democracy and its critics. New Haven: Yale University Press, 1991.

DAHL, R. Poliarquia. São Paulo: Edusp, 1997.

DAHL, R. Sobre a Democracia. Brasília: Editora da UnB, 1998

DAHL, R. Um Prefácio à Teoria Democrática. Rio de Janeiro: Jorge Zahar, 1989

DOWNS, A. Uma Teoria Econômica da Democracia. São Paulo: Edusp,2004

ELIAS, M. L. G. G. R. "Republicanismo: história e atualidade”. In: Em Tese, vol. 4 n. 1 (1), ago-dez, 2007, p. 43-64.

FERGUSON, N. The War of the World: Twentieth-Century Conflict and the Descent of the West, New York: Penguin Press, 2006

FRASER, N. "Da Redistribuição ao Reconhecimento? Dilemas da Justiça na Era PósSocialista". In: SOUZA, J. (Org.). Democracia Hoje - Novos Desafios para a Teoria Democrática Contemporânea. Brasília: Editora UnB, 2001 
GUÉHENNO, J.-M. O futuro da liberdade: A democracia no mundo globalizado. Rio de Janeiro: Bertrand Brasil, 2003

HABERMAS, J. "Três Modelos Normativos de Democracia". In: HABERMAS, J. $A$ Inclusão do Outro. Rio de Janeiro: Tempo Brasileiro, 2001

HIRST, Paul. A democracia representativa e seus limites. Rio de Janeiro: Jorge Zahar Ed., 1992

HOLANDA, C. B. Teoria das Elites. Rio de Janeiro: Jorge Zahar, 2011

HUNTINGTON, S. The Third Wave: democratization in the late twentieth century. Oklahoma City: University of Oklahoma Press, 1991

INGLEHART, R. The Renaissance of Political Culture, The American Political Science Review, Vol. 82, No. 4., 1988, pp. 1203-1230,.

LIJPHART, A. Modelos de Democracia: Desempenho e Padrões de Governo em 36 Países. Rio de Janeiro: Editora Civilização Brasileira, 2003

LIMA, A. F. de. Para a reconstrução dos conceitos de massa e identidade. Univ. Psychol. [online], vol.6, n.3, 2007 pp. 613-622.

MANIN, B.; PRZEWORSKI, A. \& STOKES, S. C. Introduction. In : MANIN, B.; PRZEWORSKI, A. \& STOKES, S. C. (eds.). Democracy, Accountability, and Representation. Cambridge : Cambridge University, 1999

MELO, M. A.. Republicanismos, liberalismo e racionalidade. Lua Nova, 2002, p. 57-84.

MICHELS, R. "A Lei de Ferro da Oligarquia". In: SOUZA, A. (org.). Sociologia Política. Rio de Janeiro: Zahar Editores, 1954

MICHELS, R. Political Parties: A Sociological Study of the Oligarchical Tendencies of Modern Democracy. New York: Free, 1968

MIGUEL, L. F. Impasses da accountability: dilemas e alternativas na representação política. Revista Sociologia Política, Curitiba, 25, 2005 p. 25-38, nov.

MOSCA, G. "A Classe Dirigente". In: SOUZA, A. (org.). Sociologia Política. Rio de Janeiro: Zahar Editores, 1954 
NUNES, F. e SILAME, T. R. Liberalismo versus republicanismo: notas sobre o conceito de liberdade. In: Em Tese, vol. 4 n. 1 (1), ago-dez, 2007, p. 43-64.

OLSON, M. The logic of colletive action. Cambridge, Mas: Harward University Press, 1965

PATEMAN, C. Participação e Teoria Democrática. São Paulo: Paz e Terra, 1992

PARETO, V. “As Elites e o uso da Força na Sociedade". In: SOUZA, A. (org.). Sociologia Política. Rio de Janeiro: Zahar Editores, 1954

PERISSINOTTO, R. As elites políticas: questões de teoria e método. Curitiba: Ibpex, 2009

PETTIT, P. "Republican freedom and contestatory democratization".In: shapiro, I.; and Hacker-Cordón,C. (Orgs.) (1999). Democracy's value. Cambridge: Cambridge University Press, 1999a.

PETTIT, P. Republicanism: a theory of freedom and government. Oxford, Oxford University Press, 1999b.

PETTIT, P. “The Consequentialist perspective", In: Baron, M.; Petit, P.; and Slote, M. Three methods of ethics. Oxford, Blackwell Publishers, 2001

PIO, C. \& PORTO, M. “Teoria Política Contemporânea: política e economia segundo os argumentos elitistas, pluralistas e marxistas". In: RUA, M. G. \& CARVALHO, M. I. V. (orgs.). O Estudo da Política. Tópicos Selecionados. Brasília: Paralelo 15, 1998.

PRZEWORSKI, Adam “Ama a incerteza e serás democrático". In: Revista Novos Estudos CEBRAP, 1984 n $^{\circ} 9$.

ROUSSEAU, J.-J. Do Contrato Social. São Paulo: Abril Cultural, 1983

SANTOS, M. L. and ROCHA, E. C. da (2011). Capital social e democracia: a confiança realmente importa?. Rev. Sociol. Polit. [online]. vol.19, 2011 n.38, pp. 43-64.

SARTORI, G. A teoria da democracia revisitada. Vol1, São Paulo: Ed.Ática., 1994

SCHUMPETER, J. (1961). Capitalismo, Socialismo e Democracia. Rio de Janeiro: Fundo de Cultura, 1961. 
SEN, A. Desenvolvimento como liberdade. São Paulo: Cia das Letras, 2000.

SILVA, D. \& SETTI, G. A. M.. Capital Social, instituições democráticas e o dilema da causalidade. Latitude. v.4, 2010 p.91-109.

SKINNER, Q. "The idea of Negative liberty: philosophical and historical perspectives", In Rorty, R.; Schneewind, J. B.; and Skinner, Q. (Eds.). Philosophy in History. Cambridge, Cambridge University Press, 1984.

SKINNER, Q. “The Republican ideal of political liberty”.In Bock, G.; Skinner, Q.; and Viroli, M. (Eds), Machiavelli and Republicanism. Cambridge University Press, 1993, 293-309.

SKINNER, Q. Liberdade antes do liberalismo. São Paulo:Editora da Unesp, 1999.

STUART MILL, J. Considerações sobre o governo representativo. Brasília, Editora da UNB, 1981

TAYLOR, C. Argumentos Filosóficos. São Paulo: Loyola. 2000.

TAYLOR, C. Sobre a liberdade. Petrópoles: Vozes, 1991.

TAYLOR, C. "What's wrong with negative liberty". In RYAN, A. (1979). The Idea of freedom, Oxford, Oxford University Press, 175-193. 1979.

WEBER, M. Economia e Sociedade. Vol. 2. Brasília: Editora da UnB, 2004.

ZAKARIA, F. O futuro da liberdade; a democracia liberal nos Estados Unidos e no mundo. Lisboa: Gradiva. 2004

\section{RESUMO}

Quais as questões semelhantes e contrárias na literatura acerca da teoria democrática contemporânea? O presente artigo tem como objetivo responder a essa questão através de uma revisão bibliográfica sobre a teoria democrática contemporânea. Estabelecemos, para fins analíticos, dois polos teóricos da democracia contemporânea: (1) democrático competitivo - que compreende o "elitismo democrático" de Joseph 
Schumpeter e o "pluralismo" de Robert Dahl; e (2) democrático popular compreendendo a "teoria participacionista" de Carole Pateman e a "teoria deliberacionista" de Jürgen Habermas. Nosso público alvo são estudantes de graduação, pós-graduação e pesquisadores em geral. Para fins didáticos, comparamos os modelos entre si, bem como os posicionamentos de tais teorias acerca da (1) participação, (2) representação política, (3) processo democrático e (4) estabilidade governamental.

PALAVRAS-CHAVES: Teoria democrática contemporânea. Democracia Competitiva. Democracia Popular.

\begin{abstract}
What issues are similar and contrary in the literature of contemporary democratic theory? This article aims to answer that question through a literature review on contemporary democratic theory. Established, for analytical purposes, two theoretical poles of contemporary democracy: (1) competitive democratic - which includes the "democratic elitism" Joseph Schumpeter and "pluralism" of Robert Dahl, and (2) popular democracy - including the "theory participationist" Carole Pateman and "theory deliberacionista" Jürgen Habermas. Our target audience is under graduate students, post graduate students and researchers in general. For didactic purposes, we compare the models to each other, as well as the positions of such theory about of (1) participation, (2) political representation, (3) the democratic process and (4) government stability.
\end{abstract}

KEYWORDS: Contemporary democratic theory. Competitive democratic. Popular democracy.

Recebido em: 11 de junho de 2013

Aceito para publicação em: 23 de julho de 2013 